\title{
STUDI KASUS TINGKAT MOTIVASI SISWA SMK TERHADAP PEMBELAJARAN IPA DI SEKOLAH
}

\section{CASE STUDY, MOTIVATION LEVEL OF VOCATIONAL SCHOOL STUDENTS ON SCIENCE LEARNING IN SCHOOL}

\author{
Sanimah $^{1}$, Sri Wahyuni ${ }^{2 *}$, Imelda Wardani Rambe ${ }^{3}$ \\ ${ }^{1,2}$ Program Studi Pendidikan Matematika, STKIP Budidaya, Sumatera Utara, Binjai, Sumatera Utara, Indonesia \\ ${ }^{3}$ Program Studi Pendidikan Matematika, STKIP Pangeran Antasari, Medan, Sumatera Utara, Indonesia \\ Email: yuni210984@gmail.com
}

Diterima: 29 Agustus 2021. Disetujui: 09 November 2021. Dipublikasikan: 25 Desember 2021

\begin{abstract}
Abstrak: Mata pelajaran Ilmu Pengetahuan Alam di Sekolah Menengah Kejuruan termasuk ke dalam kelompok mata pelajaran adaptif, yakni kelompok mata pelajaran yang berperan sebagai penunjang bagi pencapaian kompetensi keahlian atau mata pelajaran produktif. Penelitian studi kasus ini bertujuan untuk mendapatkan informasi tentang tingkat motivasi siswa dalam mempelajari IPA di SMK. Penelitian ini melibatkan subjek sebanyak 30 orang siswa program keahlian Teknik Sepeda Motor di salah satu SMK Swasta di Kecamatan Stabat. Data dijaring melalui angket siswa. Dari hasil penelitian menunjukkan bahwa pembelajaran IPA menunjang penguasaan kompetensi keahlian sehingga motivasi belajar siswa menjadi tinggi. Dari hasil pengolahan data diperoleh persentase tingkat motivasi siswa dalam pembelajaran IPA mencapai $82,9 \%$. Artinya, motivasi siswa dalam pembelajaran IPA termasuk ke dalam kategori baik sekali. Berdasarkan hasil temuan maka diperlukan tindak lanjut pengembangan metode pembelajaran yang tepat untuk mengintegrasikan keterampilan IPA dengan mata pelajaran produktif untuk meningkatkan hasil belajar siswa
\end{abstract}

Kata Kunci : Studi kasus; motivasi, siswa SMK; Pembelajaran IPA

Abstract: Natural Science subject in Vocational High School is included in the adaptive subject group, a subject that act as a support for the achievement of competency skills or productive subjects. This case study research aims to obtain information about the level of student motivation in learning science at SMK. This research involved 30 students of the Motorcycle Engineering expertise program at one of SMK in Stabat District. The data was collected through a student questionnaire. The results showed that science learning supported the mastery of skill competencies so that student learning motivation was high. From the results of data processing, the percentage of students' motivation level in science learning reached $82.9 \%$. This means that students' motivation in learning science is included in the very good category. Based on the findings, it is necessary to follow up the development of appropriate learning methods to integrate science skills with productive subjects to improve student learning outcomes.

Keywords : Case Study; motivation; SMK students; Natural Science Subject

\section{PENDAHULUAN}

Berbeda dengan Sekolah Menengan Atas (SMA), Sekolah Menengah Kejuruan (SMK) memiliki karakteristik yang khas dalam kelompok mata pelajaran. Di dalam kurikulum mata pelajaran di SMK dibagi menjadi tiga kelompok yaitu kelompok mata pelajaran normatif, adaptif, dan produktif. IPA termasuk ke dalam mata pelajaran adaptif yang berperan untuk memberikan kontribusi terhadap pencapaian kompetensi keahlian dan bersifat adaptable terhadap pembelajaran produktif. Oleh karena itu, dalam pelaksanaan pembelajaran IPA diharapkan senantiasa dihubungkan keterkaitannya dengan bidang keahlian yang sedang ditekuni oleh siswa sehingga pembelajaran IPA akan lebih bermakna bagi siswa.

Sekolah Menengah Kejuruan (SMK) bertujuan untuk menyiapkan peserta didik sebagai calon tenaga kerja yang terampil, produktif, serta memiliki kepribadian yang bermoral dan beretika agar mampu menguasai dan mengikuti perkembangan teknologi masa kini. Sejalan dengan tujuan SMK tersebut tentunya harus ditunjang dari segi lulusan peserta didik yang berkualitas. Lulusan peserta didik yang berkualitas dapat diperoleh dari sistem pengajaran yang baik yang dilakukan oleh pihak sekolah [1] Di dalam prakteknya, guru-guru IPA di SMK banyak menghadapi kendala dalam mengemas materi pembelajaran IPA agar dapat memfasilitasi siswa untuk melihat keterhubungan fakta dan konsep-konsep IPA dengan bidang keahlian mereka. Menurut Wirataoptimal, sehingga belum dapat mengembangkan kemampuan dan aktivitas siswa [2].

Jika keadaan ini dibiarkan maka dapat mengakibatkan proses belajar IPA berlangsung tidak efektif, siswa akan tetap beranggapan bahwa IPA tidak terintegrasi dengan pelajaran produktif sehingga kurang diperlukan dalam kehidupan mereka terlebih menunjang keahlian mereka di dunia industri.

Pandangan siswa terhadap mata pelajaran IPA akan sangat berpengaruh pada motivasi belajar mereka. Motivasi belajar yang tinggi akan 
menyebabkan mereka antusias dalam mengikuti pembelajaran dan mengerjakan tugas-tugas dengan maksimal sehingga dapat mencapai prestasi yang melampaui kriteria ketuntasan minimal, menguasai keterampilan ilmiah dan mengembangkan sikap ilmiahyang diharapkan. Sebaliknya, motivasi yang rendah akan berdampak pada rendahnya prestasi belajar, penguasaan keterampilan ilmiah, dan sikap ilmiah siswa. Karena motivasi merupakan salah satu kunci keberhasilan aktifitas pembelajaran siswa. Dengan adanya motivasi, proses pembelajaran diyakini menjadi lebih mudah dan hasil belajar yang maksimal dapat dicapai [3].

Menurut Sardiman bahwa hakikat motivasi belajar adalah dorongan internal dan eksternal pada peserta didik yang sedang belajar untuk mengadakan perubahan perilaku [4]. Motivasi belajar adalah keseluruhan dan daya penggerak dalam diri pesertadidik yang menimbulkan, menjamin kelangsungan dan memberikan arah kegiatan belajar, untuk mencapai tujuan pembelajaran. Oemar mengatakan Motivasi adalah suatu perubahan energi di dalam pribadi seseorang yang ditandai dengan timbulnya afekti dan reaksi untuk mencapai tujuan [5]. Sejalan dengan pendapat tersebut, selanjutnya Uno istilah motivasi berasal dari kata motif yang dapat diartikan sebagai kekuatan yang terdapat dalam diri individu tersebut bertindak atau berbuat [6].

Dalam proses belajar yang efektif, motivasi menjadi kunci dalam meningkatkan hasil belajar yang baik. Motivasi adalah kunci penting yang menjadikan seorang pembelajar efektif dalam proses belajar [7]. Sebagai salah satu faktor yang memfasilitasi hasil belajar siswa, motivasi belajar dapat diartikan sebagai dorongan dalam diri individu untuk mencapai tujuan yang ingin dicapai dalam belajar guna mendapat hasil belajar yang maksimal [8].

Sebagai mana hasil penelitian Azis dan Meilani menunjukan adanya pengaruh yang signifikan dari motivasi belajar terhadap hasil belajar siswa, dimana penelitian tersebut menekankan Penelitian ini menekankan pentingnya identifikasi motivasi belajar siswa oleh para guru sebagai dasar dalam penyusunan strategi -strategi pembelajaran serta pengadaan fasilitas belajar mengajar yang mendukung [3]. Hal serupa diungkapkan pada penelitian lain, hasil penelitian Romadhoni, et al menunjukkan bahwa Motviasi belajar berpengaruh positif terhadap hasil belajar peserta didik pada mata pelajaran gambar teknik, sehingga dapat disimpulkan bahwa motivasi dalam pembelajaran sangat penting sehingga dapat mempengaruhi hasil belajar siswa [9].

IPA sebagai mata pelajaran yang memiliki permasalahan tersendiri terutama di tingkat sekolah menengah kejuruan. Salah satu permasalahannya adalah kaitannya dalam mendukung mata pelajaran produktif. Dimana guru masih mengalami kesulitan dalam membelajarkan IPA di SMK agar dapat terintegrasi dengan matapelajaran produktif sehingga membuat siswa termotivasi untuk belajar IPA. Dengan demikian penulis memandang perlu untuk melakukan penelitian studi kasus tentang pelaksanaan pembelajaran IPA di SMK terkait dengan motivasi siswa dalam belajar IPA di SMK

\section{METODE PENELITIAN}

Jenis penelitian ini merupakan penelitian deskriptif kuantitatif dengan menggunakan metode studi kasus. Penelitian ini dilaksanakan di salah satu SMK Swasta di Kecamatan Stabat. Waktu penelitian dilakukan selama 3 bulan terhitung sejak tanggal bulan Maret sampai Mei 2021. Pada penelitian ini digunakan studi kasus tipe instrumental karena bertujuan untuk mempelajari kasus tertentu yaitu kasus tentang motivasi siswa SMK pada pembelajaran IPA di sekolah. Dalam studi kasus instrumental seorang peneliti tertarik untuk memahami sesuatu yang lebih dari sekedar kasus tertentu, peneliti tertarik dalam mempelajari kasus tertentu hanya sebagai sarana untuk suatu tujuan yang lebih besar [10].

Penelitian studi kasus ini dilaksanakan dalam waktu tiga bulan, dalam waktu tersebut sudah termasuk penelitian tahap awal yaitu pembuatan instrumen penelitian sampai penelitian tahap akhir yaitu penulisan laporan. Dalam penelitian ini yang dijadikan objek adalah SMKS di Kecamatan Stabat. Subjek diambil secara purposive sampling pada siswa kelas X.

Instrumen yang digunakan dalam penelitian ini adalah skala sikap untuk mengukur motivasi siswa SMK pada pembelajaran IPA. Angket siswa berupa lembar pernyataan sebanyak 15 butir. Angket motivasi siswa menggunakan skala Likert 1-4.

Data yang diperoleh pada penelitian ini berupa data kuantitatif hasil jawaban angket motivasi siswa pada pembelajaran IPA. diberikan kepada siswa secara daring melalui google form. Data angket motivasi dianalisis secara deskriptif kuantitatif.

\section{HASIL DAN PEMBAHASAN}

Setelah dilakukan pengolahan data terhadap angket motivasi dengan menggunakan skala Likert maka diperoleh persentase tingkat motivasi siswa dalam pembelajaran IPA mencapai $83,9 \%$. Artinya, motivasi siswa dalam pembelajaran IPA termasuk ke dalam kategori baik sekali. Berikut rincian tingkat motivasi siswa dalam pembelajaran IPA berdasarkan perhatian, kepercayaan diri, dan kepuasan siswa: 
Tabel 2. Persentase Motivasi Siswa dalam Pembelajaran IPA

\begin{tabular}{|c|c|c|c|}
\hline Indikator Motivasi & Nomor pernyataan & Persentase & Kategori \\
\hline \multirow[t]{5}{*}{$\begin{array}{l}\text { Attention } \\
\text { (perhatian) }\end{array}$} & $\begin{array}{l}\text { 1. Pembelajaran IPA mendorong saya untuk bekerja keras } \\
\text { mendapat nilai yang terbaik }\end{array}$ & $85 \%$ & Baik sekali \\
\hline & $\begin{array}{l}\text { 2. Pembelajaran IPA memotivasi saya untuk bersaing } \\
\text { dengan teman yang lain untuk memperoleh nilai yang } \\
\text { terbaik }\end{array}$ & & \\
\hline & $\begin{array}{l}\text { 3. Pembelajaran IPA mendorong saya untuk berusaha } \\
\text { menyelesaikan tugas dengan sebaik-baiknya }\end{array}$ & & \\
\hline & $\begin{array}{l}\text { 4. Pembelajaran IPA cenderung mendorong saya } \\
\text { mendorong saya menyelesaikan tugas dengan asal-asalan }\end{array}$ & & \\
\hline & $\begin{array}{l}\text { 5. Dalam mengerjakan tugas IPA saya cenderung } \\
\text { menghindar untuk mengerjakannya meskipun tugas } \\
\text { tersebut ringan }\end{array}$ & & \\
\hline \multirow[t]{4}{*}{$\begin{array}{l}\text { Confidence } \\
\text { (kepercayaandiri) }\end{array}$} & $\begin{array}{l}\text { 6. Pembelajaran IPA membuat saya terdorong untuk } \\
\text { mengerjakan tugas yang lebih menantang }\end{array}$ & $75,2 \%$ & Baik \\
\hline & $\begin{array}{l}\text { 7. Pembelajaran IPA membuat saya merasa berat untuk } \\
\text { mengerjakan tugas yang lebih menantang }\end{array}$ & & \\
\hline & $\begin{array}{l}\text { 8. Saya cenderung untuk menghindari tugas yang } \\
\text { menantang dalam pembelajaran IPA }\end{array}$ & & \\
\hline & $\begin{array}{l}\text { 9. Sayaberusaha untuk bertanggungjawab mengerjakan } \\
\text { tugas yang diberikan dalam pembelajaran IPA }\end{array}$ & & \\
\hline Satisfaction (kepuasan) & $\begin{array}{l}\text { 10. Pembelajaran IPA mendorong saya untuk mencari } \\
\text { inspirasi dari berbagai sumber }\end{array}$ & $88,7 \%$ & Baik sekali \\
\hline
\end{tabular}

Motivasi siswa kelas XI bidang keahlian Teknik Otomotif dalam mempelajari IPA termasuk pada kategori sangat baik dengan persentase sebesar $82,9 \%$. Siswa memiliki dorongan untuk mendapat nilai yang terbaik bahkan lebih baik dari temantemannya. Hal ini ditunjukkan pada saat guru mengajukan pertanyaan dalam tanya jawab, mereka berusaha untuk tunjuk tangan dan menjawab pertanyaan dengan sebaik-baiknya meskipun masih ada beberapa siswa masih mengacuhkan bahkan tidak berusaha untuk menjawab pertanyaan guru.

Besarnya motivasi siswa dalam pembelajaran turut didukung oleh tingginya keterkaitan topik yang sedang dipelajari dengan mata pelajaran keahlian. Siswa merasakan relevansi materi IPA dengan mata pelajaran produktif, bermanfaat dalam kehidupan dan menunjang dalam profesi mereka dalam kegiatan industri. Sebagaimana menurut Dimyati dan Mudjiono menjelaskan bahwa upaya guru dalam membelajarkan siswa memiliki peran yang penting untuk menumbuhkan motivasi belajar [12]. lebih lanjut menurut Setiawati mengemukakan bahwa pembelajaran dengan menghadirkan obyek yang nyata menjadikan pembelajaran berkesan [13]. Hal ini terkait dengan teori belajar yang menganggap belajar sebagai suatu proses.

Berdasarkan tabel 2 dapat dilihat nilai persentase motivasi siswa yang diukur berdasarkan indikator perhatian terhadap pembelajaran sebesar $87 \%$, kepercayaan diri dalam menyelesaikan tugas sebesar 78,9\%, dan kepuasan mengikuti pembelajaran sebesar $90 \%$. Nilai persentase ini berada pada kategori baik sampai baik sekali. Berikut grafik persentase masing-masing indikator motivasi siswa dalam pembelajaran IPA:

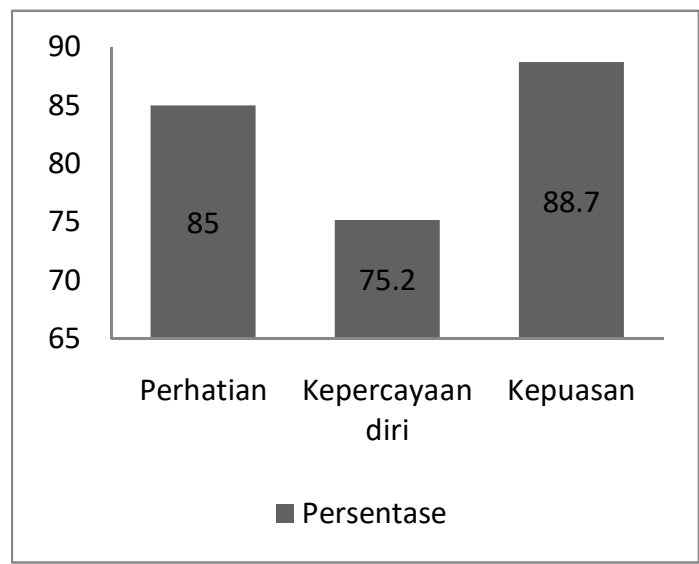

Gambar 1. Grafik Persentase motivasi siswa dalam pembelajaran IPA

Grafik di atas menunjukkan bahwa $85 \%$ siswa mencurahkan perhatiannya dalam pembelajaran, berusaha meraih nilai yang terbaik dan mengerjakan tugas-tugas yang diberikan dalam pembelajaran IPA sebaik mungkin. Hal ini dapat terlihat pada saat kegiatan pembelajaran berlangsung, sebagian besar aktifitas siswa tertuju pada guru yakni berusaha menjawab pertanyaan yang diajukan guru. Perhatian juga ditunjukkan dengan antusiasme dan rasa ingin tahu siswa terhadap materi pelajaran sehingga mereka berusaha mendapatkan jawaban dari pertanyaan guru melalui sumber-sumber belajar. Menurut Aunurrahman, siswa yang aktif akan membangun pengetahuan-pengetahuan mereka sendiri. Jika siswa terlibat aktif dalam membangun pengetahuan-pengetahuan mereka sendiri maka motivasi siswa akan meningkat sehingga berdampak pada hasil belajar siswa yang sesuai harapan [14]

Persentase kepercayaan diri siswa SMK dalam pembelajaran IPA sebesar $75,2 \%$ termasuk ke 
dalam kategori baik. Rasa percaya diri siswa sangat mendukung tingkat motivasi dalam pembelajaran. Siswa yang memiliki rasa percaya diri dalam aktifitas pembelajaran seperti menjawab pertanyaan, berdiskusi, dan mengerjakan tugas yang diberikan oleh guru maka secara otomatis akan memiliki dorongan belajar yang tinggi. Disisi lain, siswa yang tidak memiliki rasa percaya bahwa dirinya mampu mengerjakan tugas, memperoleh nilai sebaik orang lain, bahkan siswa yang berada dalam keadaan khawatir atau tertekan dalam mengikuti kegiatan pembelajaran akan memiliki motivasi belajar yang rendah.

Faktor lain yang mempengaruhi motivasi siswa dalam pembelajaran IPA adalah adanya kemauan siswa untuk tetap belajar. Hal ini ditunjukkan oleh data persentase siswa dalam mencari inspirasi dari berbagai sumber belajar sebesar $88.7 \%$. Besarnya dorongan siswa dalam mencari sumber belajar memberi kontribusi positif terhadap motivasi belajar siswa.

Rasa percaya diri dan kemauan siswa untuk tetap belajar disebut dengan faktor internal atau intrinsik. Menurut Majid Faktor internal motivasi yaitu faktor yang berasal dari dalam diri individu yang terdiri dari kebutuhan, baik kebutuhan fisik maupun psikis, persepsi individu mengenai diri sendiri yang akan mendorong dan mengarahkan perilaku seseorang untuk bertindak, harga diri dan prestasi, adanya cita-cita dan harapan masa depan, keinginan untuk maju, minat dan kepuasan kinerja [15].

\section{KESIMPULAN}

Dari hasil pengolahan data diperoleh persentase tingkat motivasi siswa dalam pembelajaran IPA mencapai 83,9\%. Artinya, motivasi siswa dalam pembelajaran IPA termasuk ke dalam kategori baik sekali. Sehingga dapat disimpulkan bahwa pembelajaran IPA menunjang penguasaan kompetensi keahlian sehingga motivasi belajar siswa menjadi tinggi.

Berdasarkan hasil temuan maka diperlukan tindak lanjut pengembangan metode pembelajaran yang tepat untuk mengintegrasikan keterampilan IPA dengan mata pelajaran produktif untuk meningkatkan hasil belajar siswa

\section{DAFTAR PUSTAKA}

[1] Kosmiyah, I. (2012). Belajar dan Pembelajaran. Yogyakarta: Teras

[2] Wirata, I Nyoman. (2019). Penerapan Model Problem Based Learning untuk Meningkatkan Motivasi Belajar IPA Siswa. Jurnal Pendidikan dan Pembelajaran IPA Indonesia. IX(3). 139145

[3] Azis, Iklima Nur \& Meilani, Rini I. (2020). Motivasi dan Hasil Belajar Siswa SMK pada Mata Pelajaran Produktif, Adaptif , dan Normatid. Jurnal Pendidikan Manajemen dan Perkantoran. V(2).154-168
[4] Sardiman. (2010). Interaksi dan Motivasi Belajar Mengajar. Jakarta: Rajawali Pers.

[5] Hamalik, Oemar, (2012). Psikologi Belajar dan Mengajar. Bandung: Sinar Baru Algasindo

[6] Hamzah, Uno, (2014). Teori Motivasi dan Pengukurannya. Jakarta: Bumi Aksara

[7] Chan, L., \& Norlizah, H. (2017). Students' motivation towards science learning and students' science achievement. International Journal of Academic Research in Progressive Education and Development, 6(4), 174-189. DOI: $10.6007 /$ ijarped/v6- i4/3716

[8] Tho, N. (2016). Knowledge transfer from business schools to business organizations: The roles absorptive capacity, learning motivation, acquired knowledge and job autonomy Introduction. 1-28. DOI: 10.1108/ JKM-082016-0349

[9] Romadhoni, E, Wiharna,O, dan Mubarak,I. (2019). Pengaruh Motivasi Belajar Terhadap Hasil Belajar Peserta Didik pada Mata Pelajaran Gambar Teknik. Journal of Mechanical Engineering Education. VI(2). 228-234

[10] Freankel. (2012). How to Design and Evaluate Research in Education Eighth Edition. US : McGraw-Hill

[11] Arikunto, S. (2006). Prosedur Penelitian. Jakarta: Rineka Cipta.

[12] Dimyati, Mudjiono. (2010). Belajar Dan Pembelajaran. Jakarta: PT. Rineka

[13] Setiawati, Gusti, A, D. (2013). Pemanfaatan Subak dalam Pembelajaran IPA (Upaya Mewujudkan Pembelajaran IPA yang Mendukung Implementasi Kurikulum 2013). Seminar Nasional FMIPA UNDIKSHA III Tahun 2013. 198-206

[14] Aunurrahman. (2012). Belajar Dan Pembelajaran. Bandung: Alfabeta.

[15] Majid, A. (2013). Strategi Pembelajaran. Bandung: Rosdakarya 